\title{
Influence of Bacille Calmette-Guérin on tuberculin skin testing in Venezuelan Amerindians in high tuberculosis burden areas
}

\author{
Mailis Maes ${ }^{1}$, Lilly M. Verhagen ${ }^{1,2}$, Dagmarys Ortega ${ }^{3}$, Gregorio L. Sánchez ${ }^{3}$, Yajaira Segovia ${ }^{4}$, Berenice \\ del Nogal ${ }^{5,6}$, Jacobus $H$. de Waard ${ }^{1,5}$ \\ ${ }^{1}$ Laboratorio de tuberculosis, Servicio Autonomo Instituto de Biomedicina, Universidad Central de Venezuela, \\ Caracas, Venezuela \\ ${ }^{2}$ Laboratory of Pediatric Infectious Diseases, Radboud University Medical Centre, Nijmegen, The Netherlands \\ ${ }^{3}$ Servicio Autónomo Centro Amazónico de Investigación y Control de Enfermedades Tropicales, Estado \\ Amazonas, Puerto Ayacucho, Venezuela \\ ${ }^{4}$ Comisión de Salud del Municipio Antonio Diaz, Dirección Regional de Salud, Ministerio de Salud, Estado Delta \\ Amacuro, Tucupita, Venezuela \\ ${ }^{5}$ Facultad de Medicina José María Vargas, Universidad Central de Venezuela, Caracas, Venezuela \\ ${ }^{6}$ Departamento de Pediatría, Hospital de Niños J.M. de los Ríos, Caracas, Venezuela
}

\begin{abstract}
Introduction: Extraordinarily high tuberculosis (TB) prevalence rates have been reported in Venezuelan Amerindians. Amerindian populations often live in geographically isolated villages where they receive little medical attention and live under precarious sanitary conditions. TB prevalence varies by ethnicity and geographic location and is generally higher in Amerindians than in non-indigenous (Creole) people.

Methodology: Between January 1, 1998 and December 31, 2009, the tuberculin skin test (TST) was administered during field operations to 9,538 Amerindian and Creole people between 0 and 94 years of age living in Venezuela. In 6,979 individuals (73\%), Bacille CalmetteGuérin (BCG) vaccination status, age, and ethnicity were recorded.Univariate and multivariate analyses were performed to determine the influence of previous BCG vaccination, age, and ethnicity on TST outcomes.

Results: Age, ethnicity, and the number of BCG vaccinations administered each had a significant influence on TST outcomes (p < 0.001). The influence of BCG vaccination on TST outcomes varied by ethnicity and was only significant in children aged between 0 and 3 years. Conclusions: The utility of TST in the diagnosis of TB infection in high TB burden settings with widespread BCG vaccination should be evaluated locally and individually as this depends on ethnicity, age, and the number of BCG vaccinations administered. In Venezuelan children 4 years of age and older, the TST remains a useful tool for the detection of TB infection, independent of BCG vaccination status.
\end{abstract}

Key words: tuberculin skin test; BCG vaccination; Amerindians

J Infect Dev Ctries 2014; 8(2):176-183. doi:10.3855/jidc.3297

(Received 09 January 2013- Accepted 21 April 2013)

Copyright ( 92014 Maes et al. This is an open-access article distributed under the Creative Commons Attribution License, which permits unrestricted use, distribution, and reproduction in any medium, provided the original work is properly cited.

\section{Introduction}

The tuberculin skin test (TST) is a simple and relatively cheap test for the detection of latent tuberculosis (TB) infection. Specificity of the TST is affected by cross-reactivity with the Bacille CalmetteGuérin (BCG) vaccine [1]. Interferon gamma release assays (IGRAs) have emerged as more specific alternatives to the TST for the diagnosis of latent TB infection [2]. However, IGRAs are far more expensive than the TST and require laboratory capacity often not present in rural areas of developing countries [3]. This limits wide implementation of these tests in lowresource settings. For this reason, it is important to investigate to what extent the TST could still be of value in the diagnosis of latent TB infection in BCGvaccinated people.

Infants in Venezuela are routinely vaccinated with BCG as recommended by the World Health Organization (WHO) to countries with high rates of TB [4]. BCG immunization coverage in Venezuela is around $87 \%$ [5]. In Venezuela, the average annual national incidence rate of $\mathrm{TB}$ is moderate $(25$ per 100,000 inhabitants) [6]. The highest TB rates are found in Amerindian tribes where TB prevalence rates over 3000 per 100,000 inhabitants were reported [7]. To investigate the utility of the TST in Amerindian populations with a high TB prevalence where BCG vaccination is widely administered, we collected data 
on BCG vaccination status, age, ethnicity, and TST outcome from 6,979 individuals from different rural areas of Venezuela and we investigated the influence of BCG vaccination, ethnicity and age on TST outcome.

\section{Methodology}

Ethical considerations

The data used for this study were collected during field operations that were carried out in the context of operational research in agreement with the Venezuelan governmental guidelines. All these operations were initiated and approved by the Venezuelan National TB Control Program (NTBP). In addition, these studies were supported by the National Asthma and Tuberculosis Expert Committee. The rising TB prevalence in indigenous populations of Venezuela was regarded as a national health emergency in 1997, after which this committee was put in charge of the formation of a report and activity plan to address the observed high TB prevalence rates in Venezuelan indigenous people. In this report, it was stated that TST is considered to be a valuable tool in TB contact tracing in Amerindian communities [8]. After 1997, TST surveys were part of the regular operational activities in Venezuelan Amerindian communities. TSTs were administered after obtaining oral informed consent from the person or the parent(s) of a child. For this study, only information on age, ethnicity, BCG status, and TST outcome was available.

People who tested TST positive were further examined for signs and symptoms of active TB disease. All subjects diagnosed with active TB were treated with a standard six-month anti-TB regime as recommended by the Venezuelan NTBP and reported in their manual [9].

The Venezuelan NTBP is the state-run TB control initiative of the government of Venezuela. It incorporates the principles of directly observed treatment short-course (DOTS), the global TB control strategy of the WHO. The program provides, free of cost, anti-tubercular drugs across the country through numerous primary health centers.

\section{Study population}

Between January 1998 and December 2009, a total of 9,538 people underwent TST testing during field operations in remote areas of Venezuela. The objective of these field operations was to identify active TB cases, for which TST was used as a first screening method. Demographic data, including age, selfidentified ethnicity, and BCG vaccination status of
$6,979(73 \%)$ subjects, were recorded in two databases: the patient database of the Centro Amazónico de Investigación y Control de Enfermedades Tropicales (CAICET) in Puerto Ayacucho, Venezuela, and the patient database of the Instituto de Biomedicina in Caracas, Venezuela. This group of 6,979 individuals for whom data about BCG vaccination status, age, and ethnicity were recorded was included in the analyses. For most of the 2,559 excluded subjects, BCG vaccination status was not recorded. The included subjects belonged to eight ethnically different Venezuelan populations: Warao, Wotjuja, Yanomami, Eñepa (or Panare), Hoti, Jivi, Curripako, and the Creoles (non-Amerindian Venezuelans).

\section{$B C G$ vaccination}

The BCG vaccine used in Venezuela is provided by Statens Seruminstitut (Copenhagen, Denmark) and is generally administered at birth or to newborns within 30 days of birth. Study subjects in which a BCG scar was detected were reported as BCGvaccinated because vaccination cards are found to be an unreliable resource of BCG vaccination status [10] and there was no other register of BCG vaccination data available.

\section{Tuberculin skin test}

The TST was performed according to the Venezuelan NTBP guidelines, in concordance with the guidelines for conducting TST surveys in highprevalence countries [11]. Two TU $(0.1 \mathrm{~mL})$ of tuberculin purified protein of Mycobacterium tuberculosis strain RT-23 (Statens Seruminstitut, Copenhagen, Denmark) was injected intradermally into the volar surface of the left forearm by trained professionals. Reading was performed by the same professional between 48 and 72 hours after administration. A palpable transverse induration with a diameter of $\geq 10 \mathrm{~mm}$ was considered positive as stated in the Venezuelan NTBP and indicated by the American Thoracic Society and Centers for Disease Control and Prevention guidelines for countries with a high TB prevalence [12].

\section{Statistical analyses}

Data about ethnicity, BCG vaccination status, age, and TST result were subjected to univariate and multivariate analyses. Odds ratios (ORs) and 95\% confidence intervals (95\% CIs) were calculated by means of regression analyses. In univariate analyses, ORs were calculated to test associations of categorical variables with TST positivity. Four multivariate 
analyses were performed. First, the results of a multivariate logistic regression model assessing the influence of ethnicity, BCG vaccination status, and age on TST outcome are presented. A multivariate linear regression model estimating the influence of multiple BCG vaccinations on TST induration size is subsequently discussed. Finally, two multivariate logistic regression models estimating the influence of BCG vaccination on TST outcome were performed. In the first model, the inclusion group was stratified by age; in the second model, the inclusion group was stratified by ethnicity. SPSS for Windows version 17.0 was used for statistical analyses.

\section{Results}

Data from 6,979 people from eight ethnically different populations were collected. A total of 4,452 people (64\%) were less than 16 years of age. Of the 6,979 included individuals, 2,272 (33\%) had positive TST results, and a total of 4,900 individuals (70\%) presented a BCG scar.

Of the 4,900 BCG vaccinated people, $35 \%$ were TST positive while only $26 \%$ of the 2,079 people without BCG vaccination were TST positive. In the BCG vaccinated population, $73 \%$ of the negative TST results were less than $1 \mathrm{~mm}$. Table 1 shows the demographic characteristics, BCG vaccination status, and TST results of all 6,979 study subjects stratified by ethnicity. In univariate analysis, the number of TST-positive subjects was significantly associated with age, ethnicity, and number of BCG vaccinations (all $p<0.001$, Table 2). The number of TST-positives was significantly higher in the Curripako, Jivi, Wotjuja, Warao, and Yanomami people compared to the Creole people. Additionally, study subjects four years of age and older were significantly more often TST-positive than those under one year of age. The percentage of TST-positives showed a linear increase with age (Figure 1). Furthermore, the percentage of TST-positive subjects increased with an increasing number of BCG vaccinations. In multivariate analysis, all variables significantly influencing TST positivity univariately remained statistically significant (Table 2).

Multiple doses of BCG vaccine are frequently administered to Venezuelan Amerindians. Vaccination cards are often lost or incompletely filled out and the people vaccinating are often inexperienced general health workers. In this study, 724 individuals had received two or more doses of BCG vaccine. A linear regression analysis adjusted for age and ethnicity
Figure 1. Percentage of TST-positives in relation to the age of study subjects

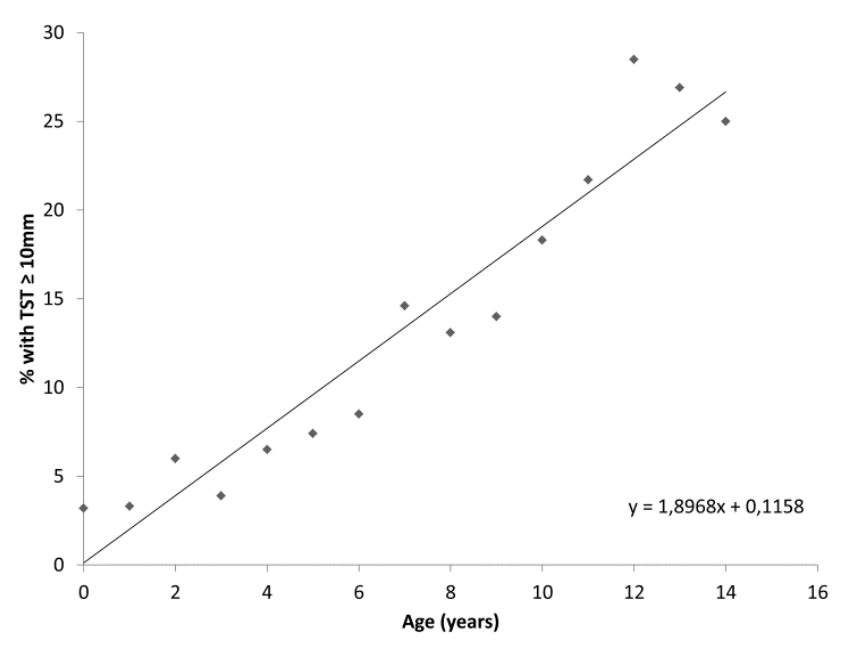

showed that TST induration size increased with each dose of BCG vaccin (Table 3).

As multiple BCG vaccinations significantly influenced TST outcome, all subjects with multiple BCG vaccinations $(n=724)$ were excluded to analyze the differences in TST outcome after only one previous BCG vaccination within different age and ethnic groups. In the 0-1 and 2-3 year age groups, significantly more TST-positive results were seen among BCG-vaccinated children compared to unvaccinated children. In contrast, children four years of age and older and adults did not show significantly more TST-positive results after previous BCG vaccination (Table 4A).

In the Wotjuja and Yanomami populations, BCGvaccinated people had a significantly higher risk of being TST-positive than unvaccinated people, while in the other populations the risk of a positive TST did not significantly differ between BCG-vaccinated and unvaccinated people (Table 4B). 
Table 1. Ethnicity, age, BCG vaccination status, and TST results of study subjects

\begin{tabular}{|c|c|c|c|c|c|c|c|c|}
\hline Ethnicity & No. & $(\%)$ & No. $<15$ Years & $(\%)$ & $\begin{array}{c}\text { No. BCG } \\
+ \\
\end{array}$ & $(\%)$ & $\begin{array}{c}\text { No. } \\
\text { TST+ }\end{array}$ & $(\%)$ \\
\hline Curripako & 70 & (1.0) & 38 & $(54.3)$ & 40 & $(57.1)$ & 24 & (34.3) \\
\hline Hoti & 138 & (2.0) & 132 & $(95.7)$ & 110 & (79.7) & 3 & $(2.2)$ \\
\hline Wotjuja & 1,232 & $(17.7)$ & 668 & $(54.2)$ & 1,054 & $(85.6)$ & 546 & (44.3) \\
\hline Eñepa & 154 & $(2.2)$ & 148 & $(96.1)$ & 100 & $(64.9)$ & 0 & $(0)$ \\
\hline Yanomami & 465 & (6.7) & 249 & $(53.5)$ & 254 & $(54.6)$ & 155 & (33.3) \\
\hline Total & 6,979 & $(100.0)$ & 4,452 & $(63.8)$ & 4,900 & $(70.2)$ & 2,272 & (32.6) \\
\hline
\end{tabular}

Table 2. Factors associated with TST positivity

\begin{tabular}{|c|c|c|c|c|c|}
\hline & & & \multicolumn{2}{|c|}{ Univariate analysis } & \multirow{2}{*}{$\begin{array}{l}\text { Multivariate analysis } \\
\text { Odds Ratio }(95 \% \mathrm{CI})\end{array}$} \\
\hline & $\begin{array}{c}\text { No. of } \\
\text { subjects }\end{array}$ & $\begin{array}{l}\text { No. of TST positive } \\
\text { subjects }(\%)\end{array}$ & Odds Ratio (95\% CI) & $P$ value & \\
\hline Age (years) & & . & & $<0.001$ & \\
\hline $2-3$ & 671 & $33(5)$ & $1.53(0.85-2.75)$ & & $1.56(0.87-2.80)$ \\
\hline $4-5$ & 666 & $46(7)$ & $2.20(1.26-3.84)$ & & $2.35(1.35-4.11)$ \\
\hline $6-7$ & 646 & $75(12)$ & $3.89(2.29-6.59)$ & & $4.43(2.60-7.52)$ \\
\hline $12-13$ & 450 & $125(28)$ & $11.39(6.82-19.02)$ & & $13.59(8.08-22.84)$ \\
\hline $14-15$ & 333 & $107(32)$ & $14.02(8.31-23.65)$ & & $17.90(10.51-30.50)$ \\
\hline$>15$ & 2,527 & $1,681(67)$ & $58.84(36.52-94.79)$ & & $53.36(33.03-86.19)$ \\
\hline Ethnicity & & & & $<0.001$ & \\
\hline Creole & 436 & $6(1)$ & 1 & & 1 \\
\hline Eñapa & 154 & $0(0)$ & - & & - \\
\hline Warao & 4,457 & $1,536(34)$ & $37.69(16.80-84.55)$ & & $29.99(13.25-67.90)$ \\
\hline Yanomami & 465 & $155(33)$ & $35.833(15.65-82.05)$ & & $21.71(9.32-50.59)$ \\
\hline No. of BCG & & & & $<0.001$ & \\
\hline 0 & 2,078 & $538(26)$ & 1 & & 1 \\
\hline 1 & 4,177 & $1,261(30)$ & $1.24(1.10-1.39)$ & & $1.26(1.09-1.46)$ \\
\hline 2 & 558 & $346(62)$ & $4.67(3.84-5.69)$ & & $1.56(1.23-1.96)$ \\
\hline 3 & 130 & $98(75)$ & $8.77(5.81-13.22)$ & & $2.52(1.57-4.03)$ \\
\hline$>3$ & 36 & $29(81)$ & $11.86(5.17-27.23)$ & & $2.81(1.15-6.91)$ \\
\hline
\end{tabular}

Table 3. Effect of multiple BCG vaccine doses on TST induration size, adjusted for ethnicity and age

\begin{tabular}{ccccc}
\hline $\begin{array}{c}\text { No. of BCG } \\
\text { vaccinations }\end{array}$ & No. of included subjects & $\begin{array}{c}\text { Mean TST induration } \\
(\mathbf{m m})\end{array}$ & Regression coefficient* & 95\% CI \\
\hline 0 & 2,078 & 4.56 & 0 & $(0.60-0.71)$ \\
2 & 4,177 & 5.41 & 0.66 & $(1.90-2.10)$ \\
3 & 558 & 11.43 & 2.00 & $(3.25-3.61)$ \\
73 & 130 & 14.00 & 3.43 & $(4.52-5.19)$ \\
\hline
\end{tabular}

\footnotetext{
*Adjusted for age and ethnicity.
} 
Table 4A. Influence of BCG vaccination status on TST outcome stratified by age group*

\begin{tabular}{|c|c|c|c|c|c|}
\hline Age group & BCG status & $\begin{array}{l}\text { No. of included } \\
\text { subjects }\end{array}$ & No. of TST+ & Odds Ratio** & $95 \% \mathrm{CI}$ \\
\hline 0-1 Year & Vaccinated & 261 & 13 & 2.99 & $(1.03-8.74)$ \\
\hline 2-3 Years & Vaccinated & 415 & 26 & 3.52 & $(1.31-9.46)$ \\
\hline \multirow[t]{2}{*}{ 4-5 Years } & Not vaccinated & 238 & 12 & 1.00 & \\
\hline & Vaccinated & 416 & 33 & 1.77 & $(0.88-3.55)$ \\
\hline 6-7 Years & Vaccinated & 411 & 52 & 1.49 & $(0.85-2.62)$ \\
\hline \multirow[t]{2}{*}{ 8-9 Years } & Not vaccinated & 151 & 27 & 1.00 & \\
\hline & Vaccinated & 432 & 50 & 0.64 & $(0.38-1.08)$ \\
\hline \multirow[t]{2}{*}{ 10-11 Years } & Not vaccinated & 111 & 21 & 1.00 & \\
\hline & Vaccinated & 397 & 74 & 1.24 & $(0.71-2.16)$ \\
\hline 12-13 Years & Not vaccinated & 79 & 15 & 1.00 & \\
\hline \multirow[t]{2}{*}{$>15$ Years } & Not vaccinated & 673 & 413 & 1.00 & \\
\hline & Vaccinated & 1,291 & 848 & 1.15 & $(0.94-1.41)$ \\
\hline
\end{tabular}

*Subjects who received multiple BCG vaccinations were excluded $(\mathrm{n}=724)$.

**Adjusted for ethnicity.

Table 4B. Influence of BCG vaccination status on TST outcome stratified by ethnicity*

\begin{tabular}{|c|c|c|c|c|c|}
\hline Ethnic group & BCG status & $\begin{array}{l}\text { No. of included } \\
\text { subjects }\end{array}$ & No. of TST+ & Odds Ratio** & $95 \% \mathrm{CI}$ \\
\hline \multirow{2}{*}{ Creole } & Not vaccinated & 76 & 1 & 1.00 & \\
\hline & Vaccinated & 360 & 5 & 0.94 & $(0.10-8.77)$ \\
\hline Curripako & Vaccinated & 36 & 14 & 1.81 & $(0.52-6.25)$ \\
\hline \multirow[t]{2}{*}{ Jivi } & Not vaccinated & 13 & 1 & 1.00 & \\
\hline & Vaccinated & 14 & 1 & 0.78 & $(0.04-17.11)$ \\
\hline Hoti & Vaccinated & 103 & 3 & - & - \\
\hline \multirow{2}{*}{ Wotjuja } & Not vaccinated & 177 & 36 & 1.00 & \\
\hline & Vaccinated & 687 & 235 & 2.19 & $(1.35-3.56)$ \\
\hline \multirow[t]{2}{*}{ Eñapa } & Not vaccinated & 54 & 0 & - & \\
\hline & Vaccinated & 100 & 0 & - & - \\
\hline Warao & Not vaccinated & 1,489 & 461 & 1.00 & \\
\hline
\end{tabular}

*Subjects who received multiple BCG vaccinations were excluded $(\mathrm{n}=724)$

**Adjusted for age.

\section{Discussion}

In a study sample of almost 7,000 Venezuelan children and adults, the percentage of TST-positive subjects was significantly associated with age, ethnicity, and the number of administered BCG vaccinations. The influence of $B C G$ vaccination on TST outcome varied by age group. In children under four years of age, a single BCG vaccine dose was significantly associated with a positive TST. This might be due to the fact that these children recently received their BCG vaccination, leading to a relatively strong immune response following TST administration. In other studies, the influence of BCG, if administered in infancy, has been found to vanish after 10 years of age [13]. We observed that even in children between 4 and 10 years of age, there was no significant difference in TST positivity rates between BCG-vaccinated and non-vaccinated children. We also showed that in two ethnic groups (the Yanomami and the Wotjuja), previous BCG vaccination had a 
significant influence on TST positivity rates, while in the majority of the ethnic populations included in our survey a single BCG vaccination did not influence TST outcome. It is remarkable that the Yanomami were one of the ethnic populations in which a significant relationship between BCG vaccination and TST results was observed, as in an earlier study including Yanomami Amerindians a high frequency of unresponsiveness to TST in recently BCG-vaccinated individuals was reported [14]. A possible explanation for this discrepancy is that the results of the earlier study, in contrast to our results, were not corrected for age while both children and adults were included. We observed that the influence of previous BCG vaccination on TST results is significantly related to age (Table 4A). Therefore, we suggest that in studies assessing TST results in BCG-vaccinated and nonBCG vaccinated individuals, the possible influence of age should be taken into account.

Another possible factor that could lead to contradicting results on the influence of BCG vaccination on TST positivity between studies is a difference in TB burden. A previous study including Warao Amerindians, one of the Venezuelan ethnic populations also included in our survey, showed that TST positivity is likely to be associated with BCG vaccination in communities with a low TB prevalence, while BCG vaccination has very little influence on TST outcomes in communities with a high TB burden [15]. This suggests that the influence of previous BCG vaccination on TST positivity is related to the TB burden in a specific setting. Wang et al. performed a meta-analysis comparing the influence of BCG on TST results in several countries. They did not observe a difference in the relative risk of a positive TST in BCG-vaccinated individuals based on geographical location [16]. However, in their meta-analysis, countries were clustered according to geographical region and not to whether they belong to the group of high TB burden countries identified by the WHO [17]. As low and intermediate burden countries can be located close to high burden countries, the absence of a significant effect of geographical region on the relationship between BCG and TST results does not necessarily indicate that this relationship is independent of the local TB burden. A study performed in Turkey, an intermediate TB burden country with high BCG coverage rates, showed a low specificity of the TST for the detection of latent TB infection [18]. Higuchi et al. also observed a low performance of the TST in discriminating between close and casual contacts in BCG-vaccinated primary school students from Japan, a low burden country [19]. In contrast, the results from studies investigating risk factors for TST positivity in The Gambia, Brazil, and Tanzania, all high burden countries, are similar to our findings [20-22]. These studies also concluded that the TST remains a useful test for the identification of children infected with $M$. tuberculosis, independent of BCG vaccination status. Thus, the effect of previous BCG vaccination on TST performance might be limited to intermediate and low burden settings. This was also suggested in a review and meta-analysis of the utility of IGRAs and TST in high burden vs. low burden settings by Dheda et al. [23]. They concluded that, in high burden settings, the TST performs reasonably well and correlates as well, or better, with proxy measures of exposure compared to IGRAs.

To our knowledge, this is the first study comparing the influence of BCG vaccination on TST positivity in different Amerindian populations residing in the same country. We observed a significant difference in the influence of previous BCG vaccination on TST outcome between populations. As a high and increasing TB burden has been consistently reported in the Venezuelan Amerindian populations included in our study [7,24,25], differences in TB burden between ethnic populations might not be the only explanation for our findings. A genetic component in the responsiveness to TST after BCG vaccination could also underlie the observed differences between ethnically different populations. The evidence for a genetic component in TB susceptibility is incontrovertible [26]. Possibly, genetic background also plays a role in TST responsiveness after BCG vaccination.

A limitation of our study was that data on sex, socioeconomic status, TB signs and symptoms and previous contact with TB cases were not available. As high prevalence of active TB has been described in the included populations $[7,24,25]$ and because our sample size was large, the percentage of people exposed to TB cases is not likely to differ widely between populations. Therefore, it is unlikely that the lack of information on previous TB exposure has led to a bias in our results concerning the influence of ethnicity on TST outcome. Sex and socioeconomic status have previously been reported to be risk factors for TST positivity $[20,27]$. Low income and low education level have been found to be associated with a positive TST [28]. As Creoles generally have higher levels of education and income than most Amerindian populations [29], the relatively low percentage of 
TST-positives in this group compared to the Amerindian populations could be partly due to the higher socioeconomic status of the Creole population.

\section{Conclusion}

We conclude that, in high TB burden settings with widespread BCG vaccination in Venezuela, the TST may remain a useful screening tool for the detection of TB infection, as a significant influence of previous BCG vaccination on TST outcome was only observed in children under four years of age and in specific ethnic populations. Therefore, ethnicity and age of the individual should be taken into account when interpreting the results of TSTs.

\section{Acknowledgements}

This work was supported by aresearch grant from SHELL Venezuela SA and TOTAL Venezuela SA. Additionally, the study was supported by the World Bank Project P008227.

\section{References}

1. Lalvani A, Millington KA (2007) T cell-based diagnosis of childhood tuberculosis infection. Curr Opin Infect Dis 20: 264-271.

2. Lalvani A, Pareek M (2010) Interferon gamma release assays: principles and practice. Enferm Infecc Microbiol Clin 28: 245-252.

3. Pai M, Kalantri S, Dheda K (2006) New tools and emerging technologies for the diagnosis of tuberculosis: part I. Latent tuberculosis. Expert Rev Mol Diagn 6: 413-422.

4. World Health Organization (2006) Guidance for national tuberculosis programmes on the management of tuberculosis in children. Geneva, Switzerland available: http://www.who.int/maternal_child_adolescent/documents/ht m_tb_2006_371/en/index.html last accessed 27 March 2013.

5. World Health Organization. Immunization surveillance, assesment and monitoring. Immunization profile - Venezuela $\begin{array}{llll}\text { (Bolivarian Republic of } & \text { Available }\end{array}$ http://www.WHO.int/immunization_monitoring/data/ven.pdf. Accessed 15 January 2011.

6. Pan American Health Organization (PAHO). Plan regional de tuberculosis 2006-2015. Available: http://www.paho.org/spanish/ad/dpc/cd/tb-reg-plan-200615.pdf. Accessed 5 January 2013.

7. Fernández de Larrea C, Fandiño C, López D, del Nogal B, Rodríguez N, Convit J, Araujo Z, de Waard JH (2002) Tuberculosis in subjects under 15 years of age in the population of Warao in Venezuela. Invest Clin. 43: 35-48.

8. Castillo A, Chaumer S, Holguin W, Manzini B, Morris M, Paris R, Sanchez G, Tuberculosis en el indígena. Reunion de expertos en astma y tuberculosis 20-22 de junio 1997. Isla de Margarita, Venezuela. Folleto 1997; Page 55.

9. Guilarte AJ, España MF, Mendez RJ, Vasquez de Salas A. Programa National de Tuberculosis. Normas oficial Venezolana del programa nacional integrado de control de la tuberculosis. Manual para coordinadores y laboratorio 2006.
10. Luman ET, Ryman TK, Sablan M (2009) Estimating vaccination coverage: validity of household-retained vaccination cards and parental recall. Vaccine 27: 2534-2539.

11. Rieder HL, Chadha VK, Nagelkerke NJ, van Leth F, van der Werf MJ, KNCV Tuberculosis Foundation (2011) Guidelines for conducting tuberculin skin test surveys in high-prevalence countries. Int J Tuberc Lung Dis 15: S1-25.

12. CDC (2000) Targeted tuberculin testing and treatment of latent tuberculosis infection. MMWR 49 (No. RR-6): 1-51.

13. Farhat M, Greenaway C, Pai M (2006) False-positive tuberculin skin tests: what is the absolute effect of BCG and non-tuberculous mycobacteria? Int J Tuberc Lung Dis 10: 1192-1204.

14. Sousa AO, Salem JI, Lee FK, Verçosa MC, Cruaud P, Bloom BR, Lagrange PH, David HL (1997) An epidemic of tuberculosis with a high rate of tuberculin anergy among a population previously unexposed to tuberculosis, the Yanomami Indians of the Brazilian Amazon. Proc Natl Acad Sci USA 94: 13227-13232.

15. Araujo $\mathrm{Z}$, de Waard $\mathrm{JH}$, de Larrea $\mathrm{CF}$, Borges $\mathrm{R}$, Convit $\mathrm{J}$ (2008) The effect of Bacille Calmette-Guérin vaccine on tuberculin reactivity in indigenous children from communities with high prevalence of tuberculosis. Vaccine 26: 5575-5581.

16. Wang L, Turner MO, Elwood RK, Schulzer M, FitzGerald JM (2002) A meta-analysis of the effect of Bacille Calmette Guérin vaccination on tuberculin skin test measurements. Thorax 57: 804-809.

17. World Health Organization. Global Tuberculosis Report 2012. Geneva, Switzerland

18. Dilektasli AG, Erdem E, Durukan E, Eyüboğlu FÖ(2010) Is the T-cell-based interferon-gamma releasing assay feasible for diagnosis of latent tuberculosis infection in an intermediate tuberculosis-burden country? Jpn J Infect Dis 63: 433-436.

19. Higuchi K, Kondo S, Wada M, Hayashi S, Ootsuka G, Sakamoto N, Harada NJ (2009) Contact investigation in a primary school using a whole blood interferon-gamma assay. Infect 58: 352-357.

20. Lienhardt C, Fielding K, Sillah J, Tunkara A, Donkor S, Manneh K, Warndorff D, McAdam KP, Bennett S (2003) Risk factors for tuberculosis infection in Sub-Saharan Africa. Am J Respir Crit Care Med 168: 448-455.

21. Almeida LM, Barbieri MA, Da Paixão AC, Cuevas LE (2001) Use of purified protein derivative to assess the risk of infection in children in close contact with adults with tuberculosis in a population with high Calmette-Guérin bacillus coverage. Pediatr Infect Dis J 20: 1061-1065.

22. Rose MV, Kimaro G, Nissen TN, Kroidl I, Hoelscher M, Bygbjerg IC, Mfinanga SG, Ravn P (2012) QuantiFERON®TB gold in-tube performance for diagnosing active tuberculosis in children and adults in a high burden setting. PLoS One 7: e37851.

23. Dheda K, van Zyl Smit R, Badri M, Pai M (2009) T-cell interferon-gamma release assays for the rapid immunodiagnosis of tuberculosis: clinical utility in highburden vs. low-burden settings. Curr Opin Pulm Med. 15: 188-200.

24. Romero-Amaro Z, JSP, Bracho A, Atencio R, Romero-Gori N, Montiel C (2008) Prevalencia de tuberculosis pulmonar en pacientes indígenas y no indígenas del estado Zulia durante el periodo 1996-2005. Kasmera. 36: 159-168. 
25. Piñate FM, Rovira JMA (2007) Estado actual de la lucha antituberculosa en Venezuela. Gaceta Médica de Caracas 115: 325-334

26. Möller M, Hoal EG (2010) Current findings, challenges and novel approaches in human genetic susceptibility to tuberculosis Tuberculosis (Edinb) 90: 71-83.

27. Verhagen LM, Hermans PWM, Warris A, De Groot R, Maes M, Villalba JA, Del Nogal B, Van Den Hof, S, Mughini Gras L, Van Soolingen D, Pinellis E, De Waard JH (2012) Helminths and skewed cytokine profiles increase tuberculin skin test positivity in Warao Amerindians. Tuberculosis 92: 505-512.

28. Mahomed H, Hawkridge T, Verver S, Geiter L, Hatherill M, Abrahams DA, Ehrlich R, Hanekom WA, Hussey GD, SATVI Adolescent Study Team (2011) Predictive factors for latent tuberculosis infection among adolescents in a high- burden area in South Africa. Int J Tuberc Lung Dis 15: 331336.

29. Montenegro RA, Stephens C (2006) Indigenous health in Latin America and the Caribbean. Lancet 367: 1859-1869.

\section{Corresponding author}

Mailis Maes

Laboratorio de tuberculosis, Instituto de Biomedicna

Al lado del Hospital Vargas, San Nicolas aprovidencia

San Jose, 1010A Caracas, Venezuela

Phone: 0058-212-8306670

Fax: 0058-212-8626807

Email: mailismaes@gmail.com

Conflict of interests: No conflict of interests is declared. 